\title{
Risk of infection among primary health workers in the Western Development Region, Nepal: knowledge and compliance
}

\author{
Narhari Timilshina ${ }^{1,2}$, Mohammad Aslam Ansari ${ }^{1}$, Vinita Dayal $^{1}$ \\ ${ }^{1}$ College of Health and Medical Sciences, AAI-DU India \\ ${ }^{2}$ University Health Network, Toronto, Canada
}

\begin{abstract}
Introduction: Without protective practices such as antiseptic hand washing, the use of sterile/surgical gloves, safe needles, sterile equipment, and safe instrument and waste disposal procedures outlined in universal precaution guidelines, basic health workers (BHWs) are at substantial risk of blood-borne infections.

Methodology: This paper draws on research conducted in 28 primary health care centers in two districts of the Western Development Region, Nepal, between 2003 and 2004. Interviews were conducted to identify the infection control knowledge and practice compliance of basic health workers.

Results: Of 100 BHWs studied, only $22 \%$ had correct knowledge of universal precautions and $73 \%$ said they follow universal precaution guidelines. A total of $62 \%$ reported that they regularly used protective gloves while handling patients and $72 \%$ reported that they never used high-level disinfection to eliminate all microorganisms (bacteria, viruses, fungi, and parasites, including bacterial endospores) from instruments and other items that would come into contact with broken skin or intact mucous membranes. Reasons for noncompliance included irregular supply of materials (31\%); lack of an autoclave and other high-level disinfection equipment (50\%); lack of knowledge and insufficient technical skills regarding universal precaution procedures (20\%).

Conclusion: Results showed that poor knowledge and an irregular supply of materials, equipment, and instruments prevented BHWs from using infection control measures. Formal training in universal precautions is urgently needed, and protective equipment must be provided and use must be monitored. Compliance to infection control procedures must be improved at primary health care units, especially among the basic health workers.
\end{abstract}

Key words: Universal Precaution; Infection control; Knowledge; Practice; Health workers

J Infect Dev Ctries 2011; 5(1):018-022.

(Received 23 December 2009 - Accepted 28 July 2010)

Copyright () 2011 Timilshina et al. This is an open-access article distributed under the Creative Commons Attribution License, which permits unrestricted use, distribution, and reproduction in any medium, provided the original work is properly cited.

\section{Introduction}

Nepal is one of the poorest and least developed nations in South Asia. Its dramatic geographic area, including the highest mountains in the world, is a great obstacle to improving the quality of health care for its population of 28 million. In many poor countries such as Nepal, most doctors are concentrated in the cities; while community health workers run health centers in rural areas [1].

Health-care workers are at risk of contracting the hepatitis B virus (HBV), hepatitis $\mathrm{C}$ virus (HCV), and human immune deficiency virus (HIV) through exposure to blood and bodily fluids (BBF). It is estimated that between 600,000 and $1,000,000$ episodes of mucous membrane exposure to blood and bodily fluids occur annually in the United Sates (US) [2,3]. About half of these exposures were not reported [4], and approximately 100,000 sharp injuries occur in the United Kingdom (UK) hospitals each year [5]. As incidences of HIV, HBV and HCV continue to increase, more attention to the risk of potential exposure to blood and bodily fluids in health care workers is needed.

Economic, social and cultural factors all contribute to the spreading of diseases. Basic health workers are front-line service providers to the community in Nepal. They work in hospitals, primary health centres and sub-health posts. With rising rates of HIV all over the world, it is necessary to take precautions to prevent infectious disease transmission in health-care settings.

Exposure to blood and bodily fluids is a serious occupational concern for health-care workers and represents a major risk for the transmission of HIV [6-8]. Universal precautions recommend taking protective and preventive measures whenever there is contact between health-care workers and the mucous membranes, blood, and bodily fluids of patients. 
Table 1. Demographic characteristics of study participants

\begin{tabular}{|l|c|}
\hline Variables & 39 \\
\hline Age (mean) & \\
\hline Gender & 69 \\
Male & 31 \\
Female & \\
\hline Work location & 17 \\
Primary health centre & 40 \\
Health post & 43 \\
Sub-health post & \\
Heath Training & 22 \\
Auxiliary health worker (AHW) & 16 \\
Auxiliary nurse midwife (ANM) & 8 \\
Health assistant (HA) & 21 \\
Community health assistant (CMA) & 2 \\
Staff nurse & 31 \\
Village health worker (VHW) & \\
\hline Source of information regarding HIV/AIDS & 43 \\
FM/Radio & 84 \\
Magazine/newspaper & 42 \\
TV & \\
\hline
\end{tabular}

Despite evidence that failure to use universal precautions increases the risk of blood-borne infections such as HIV, HBV and HCV, suboptimal adherence by health workers has been extensively reported [9-14].

\section{Methodology}

\section{Basic health workers in Nepal}

Nepal's health-care system is based on the district health system. The country is divided into 75 districts, each district being further divided into village development committees (VDCs), which are comprised of nine to eleven wards. Each district usually has one or two health centers, several health posts and sub-health posts. Health posts are staffed by health assistants (HA) who have undergone three years of clinical training and auxiliary nurse midwives (ANM) who have had undergone 15 months of clinical training. ANM are responsible for antennal care, deliveries in health posts or home, and the immunization and growth monitoring of children.

Sub-health posts are staffed by auxiliary health workers (AHW), also known as community medical assistants (CMA), who have had 18 months of clinical training. Maternal and child health workers (MCHW) provide the immunization and antenatal care at a sub-health post level. These women have had three months of training followed by a six-week refresher course.
Health assistants and auxiliary health workers are able to diagnose and treat common illnesses in rural communities. Both health posts and sub-health posts employ a village health worker (VHW) who has had three months of training and is responsible for house visits, following up with tuberculosis cases, and assisting with immunization programs.

\section{Source of sample}

Staff from the 28 primary health centres (PHC) in the Kaski and Tanahau districts were surveyed. Ethical approval for the study was obtained from the Ministry of Health, Department of Health Services, and the Nepal Health Research council. Forty-nine health institutions, including the primary health centre (PHC), 12 health posts and 34 sub-health posts, and excluding the western regional hospital were included in the study from the Kaski district. Similarly, in the Tanahun district, two PHCs, 13 health posts and31 sub-health posts were included. Stratified proportionate random sampling was used to select the basic health workers from each study site. Size and staffing data of primary health care centers (PHC, HP and SHP) were obtained from the respective district health offices. The respondents were selected from the staff list provided by the district health office of each respective district. A total sample size of $100 \mathrm{BHWs}, 50$ from the Kaski 
Table 2. Distribution of respondents according to follow-up universal precaution

\begin{tabular}{|l|c|c|c|}
\hline Statements & Regular & Sometimes & Never \\
\hline Follow-up universal precaution & 73 & 26 & 1 \\
\hline $\begin{array}{l}\text { Decontamination of instruments and } \\
\text { equipment }\end{array}$ & 14 & 14 & 72 \\
\hline $\begin{array}{l}\text { Sterilization of instruments and } \\
\text { equipment }\end{array}$ & 95 & 5 & 0 \\
\hline $\begin{array}{l}\text { Wearing gloves while attending to any } \\
\text { patient with open wounds }\end{array}$ & 62 & 36 & 2 \\
\hline $\begin{array}{l}\text { Wearing gloves while attending to } \\
\text { HIV/AIDS patients }\end{array}$ & 73 & 16 & 46 \\
\hline $\begin{array}{l}\text { Dispose blood and blood products with } \\
\text { solid waste }\end{array}$ & 38 & 5 & 2 \\
\hline $\begin{array}{l}\text { Hand washing before and after } \\
\text { attending to each patient }\end{array}$ & 93 & 65 & 17 \\
\hline Educating the public regard HIV/AIDS & 18 & & \\
\hline
\end{tabular}

district and 50 from the Tanahun district, were selected. The study population consisted of all basic health workers (VHW, AHW, ANM, HA and staff nurses) who were working in different government health institutions in the Kaski and Tanahau districts. Personal interviews were conducted to collect the data. The interviews were conducted at the participants' workplaces. The information from the questionnaire was entered into EPI-Info version 6.04 software (Centers for Disease Control and Prevention, Atlanta, Georgia, USA). Simple statistical tools such as mean, median, frequency, and percentage were used to analyze the data.

\section{Results}

The study findings indicate that only $22 \%$ of BHWs had correct knowledge of universal precautions. A total of $73 \%$ BHWs said they used universal precautions while treating patients. The study also found that almost $95 \%$ of respondents regularly sterilized the equipment and instruments before the immunization and treatment of any patients. Hence it may be concluded that, while almost all BHWs claimed to use universal precautions and understood the necessity of using sterile equipment, most of the workers may not have been following the necessary procedures correctly. Only $62 \%$ of BHWs reported always using gloves; $72 \%$ of the BHWs reported that they had never used decontaminated instruments (i.e., instruments from which microbial spores have been destroyed or removed in addition to physical and chemical substances); $63 \%$ BHWs washed their hands regularly before and after attending to each patient; and $46 \%$ disposed medical waste in their workplace.
A large majority of BHWs reported that the supply of essential materials (e.g. disposable syringes and needles, hand gloves, soap, towels, running water in the facility) were not adequate to meet their daily or routine requirements. Furthermore, while a large majority of BHWs (72\%) reported that they have private exam rooms and exam tables available, only $50 \%$ BHWs had an autoclave/HLD facility. Inadequate blood testing facilities, inadequately trained health staff, poor management of services, lack of proper instruments, and fear of accidental transmission of HIV were the problems faced by BHWs. Finally, 55\% of the BHWs reported that their workplaces do not have proper biohazard disposal containers.

\section{Discussion}

The increasing prevalence of hepatitis B, hepatitis $\mathrm{C}$ and $\mathrm{HIV}$ requires compliance with universal precaution guidelines to reduce occupational transmission of infections. BHWs should follow certain universal precautions while attending to all patients. These precautions include hand washing, and cleaning, decontaminating and sterilizing all instruments. Health-care workers in developing countries inconsistently practice universal precautions and are regularly exposed to blood in the course of their work via needle stick injuries, splash incidents, and direct contact [15].

Kermode et al. [16] examined occupational exposure to blood and risk of blood-borne virus infection among health-care workers in rural India and found that $63 \%$ of workers reported at least one percutaneous injury in one year, compared to $24 \%$ in the US $[16,17]$. 
Table 3. Distribution of participant's response regarding adequate and timely supply of materials in primary health centre

\begin{tabular}{|l|c|c|}
\hline & Yes & No \\
\hline Supply of disposable syringe and needle & 69 & 31 \\
\hline Supply of gloves & 64 & 36 \\
\hline Running water, soap and towel in exam room & 65 & 35 \\
\hline Private exam room & 72 & 28 \\
\hline Exam table & 91 & 9 \\
\hline Autoclave/HLD & 50 & 50 \\
\hline Instruments & 75 & 25 \\
\hline Proper disposal container & 45 & 55 \\
\hline Facility for storage of instruments & 75 & 25 \\
\hline
\end{tabular}

The findings of the current study suggest that basic health workers do not have sufficient knowledge of universal precautions. The majority of respondents $(59 \%)$ did not answer universal precaution knowledge questions. Only $22 \%$ of the workers reported accurate knowledge of universal precautions as an effective barrier between health workers and patients to prevent the transmission of infections. Similarly, inadequate knowledge of universal precautions was found among the hospitalbased health workers in Nepal [18]. These levels of knowledge were very low compared to other parts of world [12,19]. A significant number of hospitalbased workers $(73 \%)$ reported that they use universal precautions. A large majority of respondents (93\%) reported that they wash their hands before and after attending to each patient. This hand washing practice was similar to that of western countries [20].

When health services are provided, disposable needles and syringes and blood and bodily fluids should be placed in puncture-resistant containers near the area in which they were used. Only 55\% of workers reported having a disposal container in their workplace, and even fewer respondents (38\%) reported proper disposal of blood and blood products with solid waste. Furthermore, the majority of health workers $(46 \%)$ reported that they never properly dispose of solids, which can be a potential source of cross-infection.

Several factors may contribute to this high prevalence of risky practices and breach of infection prevention guidelines, including the limited availability of basic supplies and infection control materials. Health-care institutions should provide a safe environment for caregivers by establishing or updating infectious disease management policies, ensuring that health-care workers have the necessary equipment, and ensuring that all workers follow universal precautions for safe handling of blood and bodily fluids. Some key issues regarding universal precautions which need to be remedied include providing an adequate supply of instruments, as well as facilities for the proper disposal of blood and blood products, and adequate sterilization and decontamination equipment at primary health care units. Strictly adopting all universal precautions in every health institution is very important to protect all the health-care staff. A total of $38 \%$ of respondents reported inadequate blood testing facilities as one of the major problems they face in complying with universal precautions. Furthermore, $22 \%$ reported that the lack of basic instruments and core facilities as a major problem.

This study illustrates the need to improve the infection control practices in primary health-care centers. Although this study may not be applicable to all BHWs in Nepal, it gives insight into the implementation of universal precautions in rural and urban basic health centres and hospitals in developing countries. Development of guidelines for the prevention and control of occupational exposure of health-care workers to bodily fluids and blood-borne pathogens in the workplace is urgently needed.

In conclusion, occupational exposure to bodily fluids and blood-borne pathogens is very high for basic health workers in Nepal. The level of knowledge of universal precautions was limited, resulting in poor precautionary practice. The issue of conformity to universal precaution should not be left to the discretion of the BHWs; it should be mandatory. To this end, we recommend a more pragmatic approach through which training, infection control supplies, staffing, and the chain of infection control could be enhanced. In addition, a regular system for reporting exposure is important in promoting safety and in planning infection prevention initiatives. 


\section{Acknowledgements}

We thank all the basic health workers who were surveyed. Thank you also to Dr. Arvinada Dayal and Dr. Alison Anderson for academic support and to the Nepal Health Research Council (NHRC) for funding.

\section{References}

1. Shankar PR, Partha P, Shenoy N (2002) Self medication and non-doctor prescription practices in Pokhara Valley, western Nepal: a questionnaire-based study. BMC Fam Pract. 17: 3 17.

2. Moloughney BW (2001) Transmission and postexposure management of bloodborne virus infectious in the health care setting: where are we now? Can Med assoc J 165: 445451.

3. Gillen MR, Davis M, McNary JC, Boyd A, Lewis J (2002) Sharp injury recordkeeping activities and safety product use in California health care facilities: Pilot study results from the sharps injury control program. AM J infect Control 30: 269-276.

4. International health care workers, safety centre (2003) Exposure prevention information network (EPINet) data reports. Charlottesville; University of Virgina (Online) Available:

healthsystem.virginia.edu/internet/epinet/EPINet-2003report.pdf. Accessed 24 December 2010.

5. Trim JC and Elliott TS (2003) A review of sharps injuries and preventive strategies. J Hosp Infect 53: 237-242.

6. International Labor Organization and World Health Organization, International Labor Office, Geneva (2005) Joint ILO/WHO guidelines on health services organization and HIV/AIDS. Available: http://www.who.int/hiv/pub/prev_care/who_ilo_guidelines.p df. Accessed 23 November 2009.

7. W-Gabriel Y (2004) Assessment of the safety of injections and related medical practices in health institutions in SNNPs, Ethiopia. Department of Community Medicine. Addis Ababa: Addis Ababa University; 2004.

8. Hutin Y, Hauri A, Chiarello L, Catlin M (2003) Best infection control practices for intra-dermal, subcutaneous, and intramuscular needle injections. Bull WHO 81: 491-500 Available:

http://www.who.int/bulletin/volumes/81/7/Hutin0703.pdf. Accessed 23 November 2009.

9. Ekwueme DU, Weniger BG, Chen RT (2002) Model-based estimates of risks of disease transmission and economic costs of seven injection devices in sub-Saharan Africa. Bull WHO 80: 859-870 Available: http://www.who.int/bulletin/archives/80(11)859.pdf. Accessed 23 November 2009.

10. Knight VM and Bodsworth NJ (1998) Perceptions and practice of universal blood and body fluid precautions by registered nurses at a major Sydney teaching hospital. J Adv Nurs 27: 746-751.
11. Cutter J and Jordan S (2004) Uptake of guidelines to avoid and report exposure to blood and body fluids. J Adv Nurs 46: 441-452.

12. Bennett $G$ and Mansell I (2004) Universal precautions: a survey of community nurses' experience and practice. J Clin Nurs 13: 413-421.

13. Ferguson KJ, Waitzkin H, Beekmann SE (2004) Critical incidents of nonadherence with standard precautions guidelines among community hospital-based health care workers. J Gen Intern Med 19: 726-731.

14. Angtuaco TL, Oprescu FG, Lal SK (2003) Universal precautions guideline: self-reported compliance by gastroenterologists and gastrointestinal endoscopy nurses - a decade's lack of progress. Am J Gastroenterol 98: 24202423.

15. Sagoe-Moses C, Pearson RD, Perry J, Jagger J (2001) Risks to health care workers in developing countries. N Engl J Med. 345: 538-541.

16. Kermode M, Jolley D, Langkhan B, Mathew S, Crofts N (2005) Occupational exposure to blood and risk of blood borne virus infection amongst health workers in rural north India health settings. AM J infect Control 33: 34-41.

17. Hersey JC and Martin LS (1994) Use of infection control guidelines by workers in health care facilities to prevent occupational transmission of $\mathrm{HBV}$ and $\mathrm{HCV}$; results from national survey. Infect control hosp Epidemiol 15: 243-252.

18. Paudyal P, Simkhada P, Bruce J (2008) Infection control knowledge, attitude, and practice among Neplease health care workers. Am J Infect Control 36: 595-597.

19. Reda AA, Vandeweerd JM, Syre TR, Egata G (2009) HIV/AIDS and exposure of healthcare workers to body fluids in Ethiopia: attitudes toward universal precautions. J Hosp Infect 7: 163-169.

20. Stein AD, Makarawo TP, Ahmad MF (2003) A survey of doctors' and nurses knowledge, attitudes and compliance with infection control guidelines in Birmingham teaching hospitals. J Hosp Infect 54: 68-73.

21. Colin Pfaff (2004) Midlevel primary health workers in Nepal. SA Fam Pract 46 Available: http://www.safpj.co.za/index.php/safpj/article/viewFile/41/4 1. Accessed 23 November 2009.

\section{Corresponding author}

Timilshina Narhari

University Health Network

Toronto General Hospital

200 Elizabeth Street, Room EN 13-222

Toronto, Canada M5G 2C4

Phone: (416) 340-4800 ext. 6152

Email: narhari2k@yahoo.com

Conflict of interests: No conflict of interests is declared. 